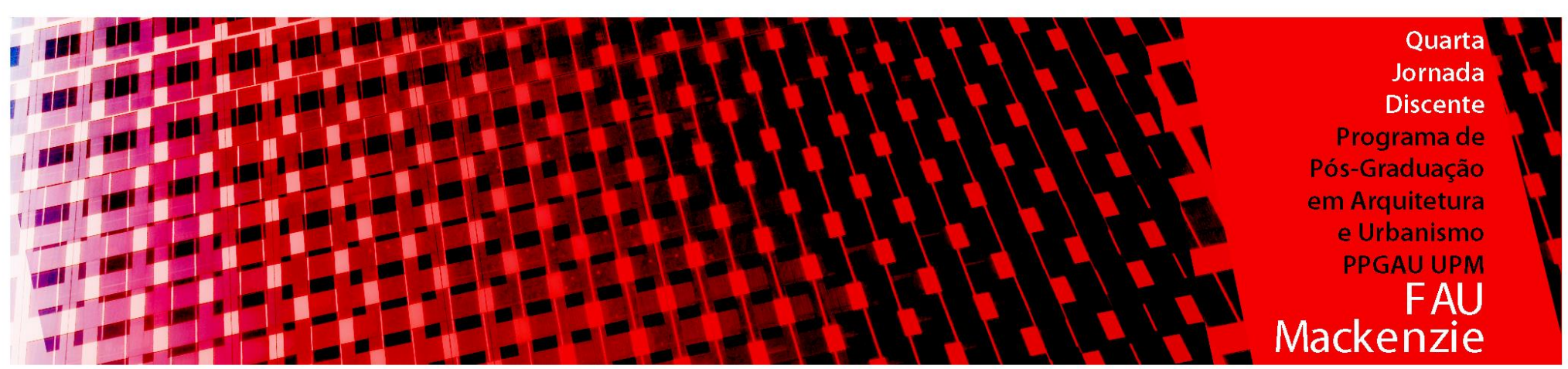

\title{
Panorama Histórico da Pré-fabricação em Concreto Armado na Produção Habitacional
}

\section{Historical Overview of Precast Reinforced Concrete in Housing Production}

\author{
Isabella Silva de Serro Azul ${ }^{1}$, Maria Augusta Justi Pisani ${ }^{2}$
}

\footnotetext{
${ }^{1}$ Mestre pela Faculdade de Arquitetura e Urbanismo da Universidade Presbiteriana Mackenzie, Rua da Consolação 930, Brasil, isabellasazul@gmail.com

${ }^{2}$ Professora do PPGAU da Universidade Presbiteriana Mackenzie, Rua da Consolação 930, Brasil, augustajp@gmail.com
} 


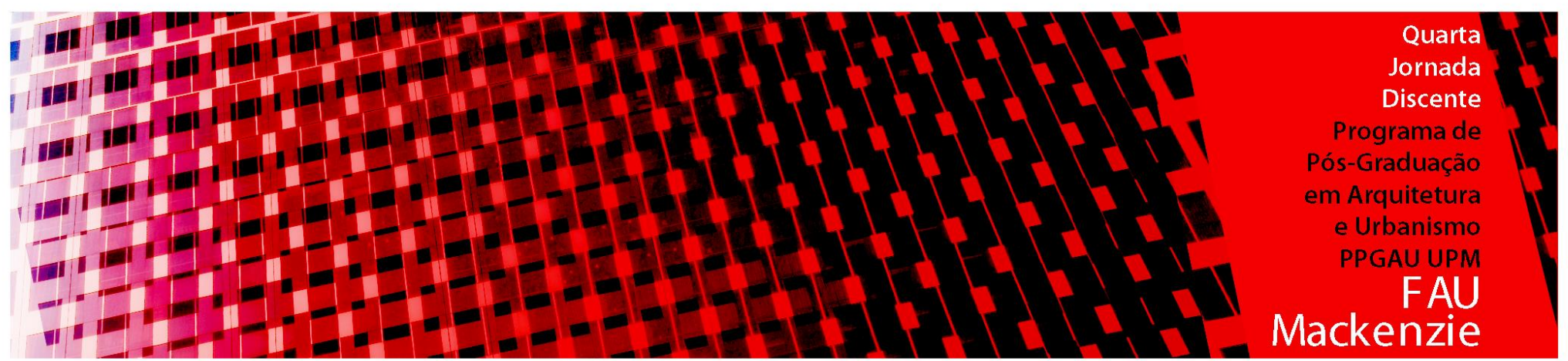

\title{
RESUMO
}

No Brasil, a maioria dos edifícios habitacionais são projetados e construídos com técnicas construtivas moldadas in loco. O déficit habitacional brasileiro e a baixa qualidade construtiva das habitações de interesse social (HIS) são questões importantes que poderiam ser melhoradas com o uso da pré-fabricação devido às características da própria definição dessa técnica construtiva. O objetivo deste artigo é traçar um panorama histórico da pré-fabricação de concreto armado com enfoque na habitação no Brasil, considerando os antecedentes internacionais. O método empregado para a realização desta pesquisa inclui levantamento de dados secundários em livros, teses, dissertações, revistas, websites, artigos técnicos e científicos e levantamento de imagens in loco realizados durante o desenvolvimento da Dissertação e do Trabalho Final de Graduação (TFG), ambos realizados na Faculdade de Arquitetura e Urbanismo da Universidade Presbiteriana Mackenzie. Apesar das características da pré-fabricação serem consideravelmente vantajosas para a construção civil, essa técnica construtiva nunca fora utilizada em grande escala no Brasil para a produção habitacional, o que demonstra uma incoerência dos programas habitacionais que buscam atender ao déficit habitacional brasileiro com técnicas construtivas artesanais.

Palavras-chave: sistemas construtivos, pré-fabricados de concreto armado, habitação

\begin{abstract}
In Brazil, most of the residential buildings are designed and built using handcrafted construction techniques. The Brazilian housing deficit and the low constructive quality of housing of social interest (HIS) are important issues that could be improved with the use of prefabrication due to the characteristics of the definition of this constructive technique. The objective of this article is to outline a historical overview of the precasting of reinforced concrete focusing on housing in Brazil, considering the international background. The method used to carry out this research includes the collection of secondary data in books, theses, dissertations, magazines, websites, technical and scientific articles and on-site imaging carried out during the development of the Dissertation and Final Graduation Work (TFG), both held at the Faculty of Architecture and Urbanism of the Mackenzie Presbyterian University. Although prefabrication characteristics are considerably advantageous for civil construction, this constructive technique has never been used in large scale in Brazil for housing production, which demonstrates an incoherence of housing programs that seek to meet the Brazilian housing deficit with artisanal construction techniques.
\end{abstract}

Key-words: construction systems, prefabricated reinforced concrete, housing 


\section{INTRODUÇÃ̃O}

Diversos países utilizaram a pré-fabricação em programas habitacionais para enfrentar situações de déficit de moradias, como ocorrido na França e na Alemanha nos períodos de pós-guerra. No Brasil, a maioria dos edifícios residenciais são projetados e construídos com técnicas construtivas moldadas in loco. Em contrapartida, em edifícios comerciais e industriais, as inovações tecnológicas, como sistemas construtivos industrializados, são empregados com maior frequência e aumentam o retorno financeiro dos empreendimentos (DONIAK, 2017).

O déficit habitacional brasileiro e a baixa qualidade construtiva das habitações de interesse social (HIS) são questões importantes que poderiam ser melhoradas com o uso da pré-fabricação devido às características da própria definição dessa técnica construtiva, como a produção em série, a possibilidade de redução de custos, a rapidez da execução e o controle de qualidade dos componentes.

A pré-fabricação nunca fora utilizada em grande escala na habitação do Brasil, apesar do primeiro edifício pré-fabricado de concreto armado com múltiplos pavimentos do país ter sido o Conjunto Residencial da Universidade de São Paulo (CRUSP) em 1961, projetado pelos arquitetos Eduardo Kneese de Mello, Sidney de Oliveira e Joel Ramalho (VASCONCELOS, 2002). Algumas experiências habitacionais isoladas foram realizadas no período do Banco Nacional da Habitação (BNH), como os conjuntos residenciais Parque Novo Irajá e Padre Miguel no Rio de Janeiro. Nos últimos anos, outras empresas construíram edifícios habitacionais pré-fabricados de concreto armado para o Programa Minha Casa Minha Vida (PMCMV).

O objetivo deste artigo é traçar um panorama histórico da pré-fabricação de concreto armado com enfoque na habitação no Brasil, considerando os antecedentes internacionais.

\section{MÉTODOS}

O método empregado para a realização desta pesquisa inclui levantamento de dados secundários em livros, teses, dissertações, revistas, websites, artigos técnicos e científicos e levantamento de imagens in loco realizados durante o desenvolvimento da Dissertação ${ }^{1}$ e do Trabalho Final de Graduação (TFG) ${ }^{2}$, ambos realizados na Faculdade de Arquitetura e Urbanismo da Universidade Presbiteriana Mackenzie.

\section{RESULTADOS E DISCUSSÃO}

Vasconcelos (2002) afirma que o pré-moldado de concreto armado surgiu junto com o próprio material pois nas suas primeiras experiências os elementos já eram produzidos fora do seu local de uso. Segundo Milman (1971), o primeiro edifício construído com um sistema pré-fabricado de concreto armado foi em 1897 no atual País de Gales.

\footnotetext{
${ }^{1}$ A Dissertação Sistemas Construtivos Pré-fabricados de Concreto Armado: Habitações Contemporâneas no Brasil foi desenvolvida no período de ago. 2016 a jun. 2018 com a orientação da Profa. Dra. Maria Augusta Justi Pisani no Programa de Pós-graduação da Faculdade de Arquitetura e Urbanismo da Universidade Presbiteriana Mackenzie. O trabalho foi realizado com apoio da Coordenação de Aperfeiçoamento de Pessoal de Nível Superior (CAPES).

${ }^{2}$ O TFG foi desenvolvido no período de ago. de 2015 a jun. de 2016; e orientado pelos professores Dr. Valter Luís Caldana Jr. e Dra. Maria Augusta Justi Pisani na Faculdade de Arquitetura e Urbanismo da Universidade Presbiteriana Mackenzie em parceria com a École d'architecture de la ville et des territoires à Marne-la-Vallée (ENSA VT) e com a Companhia de Desenvolvimento Habitacional e Urbano (CDHU). Durante o processo foram realizados diversas atividades, entre elas destacam-se os levantamentos in loco nos conjuntos habitacionais em Paris; a participação no Workshop sobre os Grandes Conjuntos de Paris em outubro de 2015.
} 
Com a Primeira Guerra Mundial, a demanda habitacional na Europa cresceu devido às destruições causadas pela guerra, principalmente na Alemanha que estava em período de crise econômica devido ao tratado de paz (HOBSBAWN, 2009). As políticas habitacionais eram distintas nos países europeus e a ideia de utilizar os benefícios da pré-fabricação para alojar a população estava em discussão.

O I Congresso Internacional da Arquitetura Moderna (CIAM), realizado em 1928 na Suíça, reuniu profissionais de diversos países para discussões sobre os princípios adotados pelo movimento. As declarações do evento apontam que os arquitetos e urbanistas modernistas visavam à racionalização, ao aumento da produtividade e à produção em série, que são características intrínsecas da construção industrializada (CONRADS, 1970, tradução nossa).

Um dos fundadores do I CIAM foi o arquiteto alemão Ernst May. Ele propôs a realização do II CIAM em Frankfurt no ano de 1929 com a questão habitacional como tema principal. May foi responsável por um programa de habitação popular conduzido em Frankfurt de 1924 a 1930, no qual foram construídas moradias na proporção de 1 unidade para cada 11 habitantes da cidade. As habitações nos bairros Praunheim e Hohenblick foram projetadas e executadas com sistemas construtivos racionalizados para diminuir o custo das obras e aumentar a rapidez de execução. Foram estabelecidas fábricas nos municípios para a pré-fabricação de painéis em concreto leve e lajes pré-moldadas (POLETO, 2011).

As 1500 habitações de Praunheim foram a primeira e maior experiência com o sistema construtivo pré-fabricado Frankfurter Montageverfahren, que significa método de montagem de Frankfurt (fig. 1). Primeiramente, foram construídas casas unifamiliares de três andares cujas estruturas poderiam ser executadas por 18 trabalhadores em um dia e meio de trabalho. Durante a segunda fase, a partir de 1927, foram construídas habitações multifamiliares. Na terceira fase, a partir de 1928, as áreas das plantas tiveram que ser reduzidas devido à crise econômica alemã (GAILHOFER, 2016, tradução nossa).

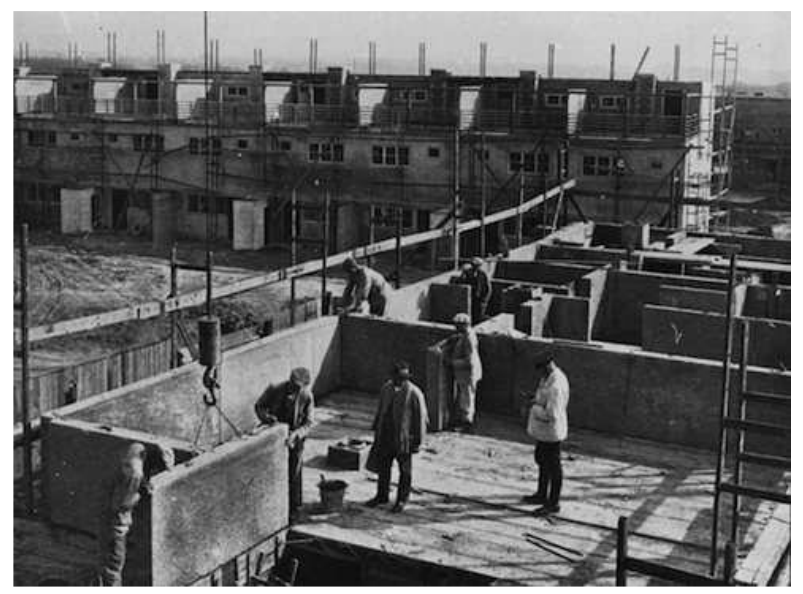

Fig. 1- Construção em Praunheim

Fonte: FRANKFURT (1926, n.p.)

Em 1930, o tema do $3^{\circ}$ CIAM, realizado em Bruxelas, foi a racionalização dos métodos construtivos. $\mathrm{O}$ assunto foi discutido nas conferências do congresso e abordava também a questão habitacional, como na apresentação do arquiteto Walter Gropius, um dos vice-presidentes da entidade (REGINO; PERRONE, 2009).

Apesar das discussões e das experiências com sistemas construtivos industrializados, até 1950 as estruturas de concreto armado moldadas in loco foram mais utilizadas do que as pré-fabricadas. No entanto, após o fim da Segunda Guerra Mundial em 1945, os países europeus começaram a reconstruir as suas cidades utilizando a pré-fabricação devido à necessidade de completar as obras com rapidez e diminuir o custo (MILMAN, 1971).

O elevado déficit habitacional da Europa na época fez com que fossem construídos grandes conjuntos habitacionais em diversos países. O sistema construtivo utilizado nesses casos era composto por peças provenientes do mesmo fornecedor, o que é definido por Bruna (2017) como 
ciclo fechado de produção. Este pode ser um dos motivos pelos quais os edifícios apresentam uma arquitetura repetitiva e pouco flexível, como nos casos dos conjuntos Les Courtillières (fig. 2), do arquiteto Emile Aillaud; e do George Contenot, de Jacques Bourgeois e Joseph Bukiet (fig. 3), ambos na França e projetados em 1954 com componentes pré-fabricados de concreto armado.
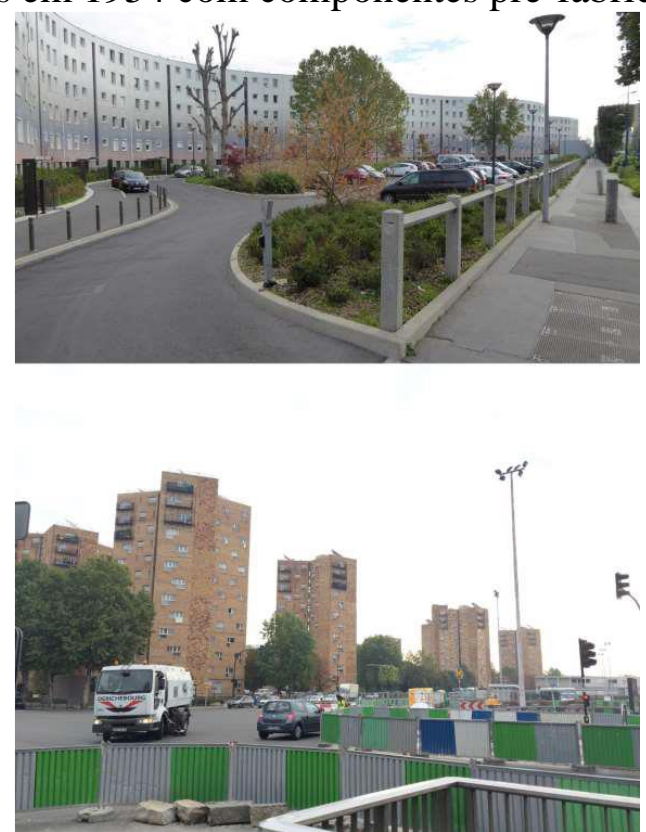

Fig. 2 - Les Courtillières, subúrbio de Paris Fonte: Acervo próprio (2015)
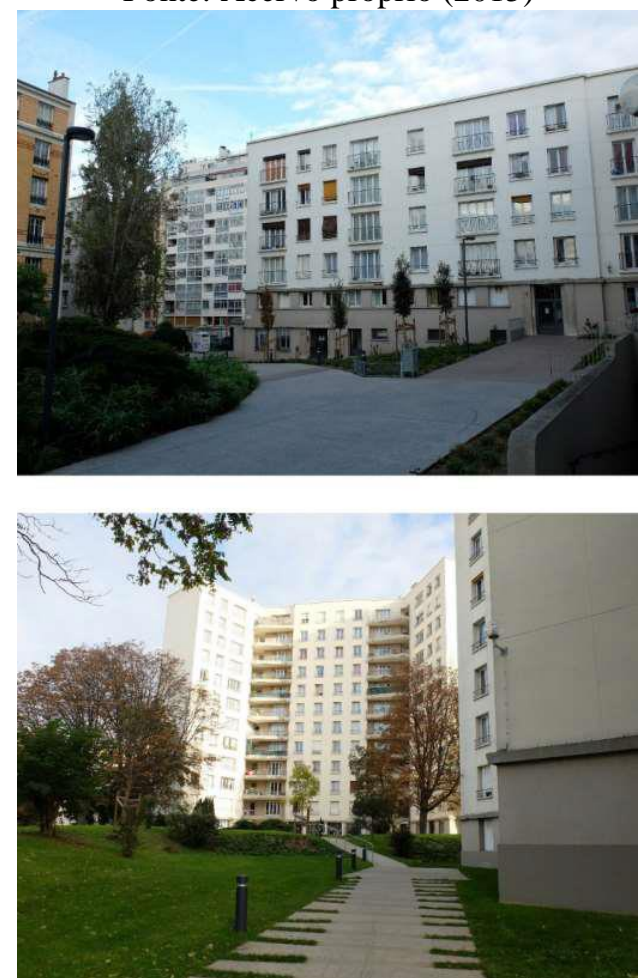

Fig. 3 - Edifícios do conjunto George Contenot em Paris Fonte: Acervo próprio (2015)

A pré-fabricação possibilitou a produção em série (fig. 4) de painéis de concreto, escadas, estruturas e elementos de banheiro para os conjuntos habitacionais. Cada processo foi designado pela empresa ou arquiteto que o implementou: Camus, em Le Havre e exportado para a União Soviética; Estiot nas habitações de Haut-du-Lièvre em Nancy; e Tracoba no conjunto Pierre Collinet em Meaux (DUFAUX; FORCAUT, 2004, tradução nossa). 

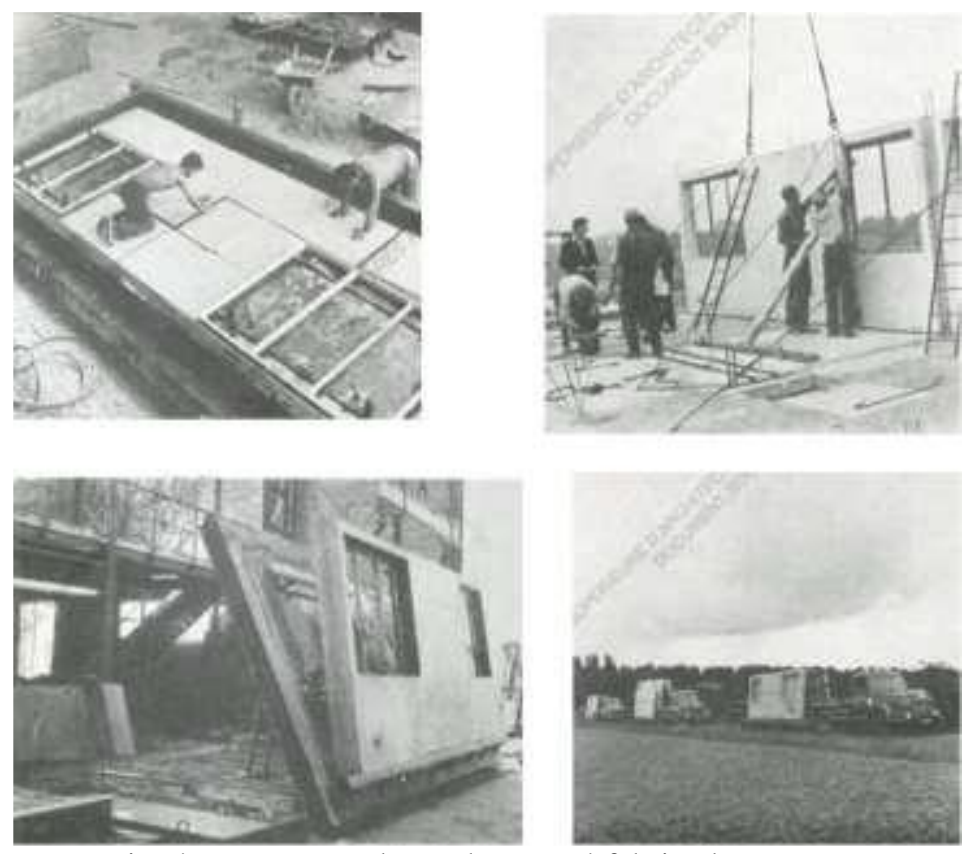

Fig. 4 - Processos da produção pré-fabricada na França

Fonte: L'ARCHITECTURE D'AUJOURD'HUI (1956, p. $96-99$ ) in: CERCEAU (2013, p. 110)

$\mathrm{Na}$ década de 1960, as situações de marginalização e insalubridade nos grandes conjuntos começaram a ser criticadas pela sociedade. Os edifícios apresentavam problemas com a falta de manutenção; desempenhos acústico e térmico precários; e patologias estruturais (DUFAUX; FORCAUT, 2004, tradução nossa).

Na década de 1980 foram registrados casos de violência, saques, incêndios e assassinatos em vários desses grandes conjuntos habitacionais. As discussões sobre a situação das periferias das cidades francesas ficaram mais intensas. Entre as diversas propostas de intervenção, a demolição foi considerada nos casos em que os edifícios estavam mais danificados. Em 1983, as primeiras torres no conjunto Minguettes, em Lion, foram destruídas. Posteriormente, diversos edifícios em outras cidades também foram demolidos (ABRAM, 1999, tradução nossa).

Após 1980, a deterioração dos edifícios construídos no período pós-guerra e a sua rejeição social fizeram com que a produção de ciclo fechado entrasse em decadência, enquanto os de ciclo aberto se consolidava na Europa (SALAS, 1988). Nos anos seguintes, foram feitas mais demolições, apesar delas configurarem uma celeuma social devido às tensões provocadas pelos despejos (SERAFINE, VINCENDON, 2015, tradução nossa).

Gropius (1924 apud GUINSBURG; KOUDELA, 2013) atribui as características depreciativas de monotonia e rigidez na arquitetura dos grandes conjuntos europeus ao projeto e não à técnica construtiva utilizada. Ele afirma que é possível criar espaços e composições interessantes com componentes pré-fabricados. A falta de flexibilidade da linguagem arquitetônica também pode estar relacionada com a produção de ciclo fechado que limita a procedência dos componentes a uma única empresa fornecedora. Já o ciclo aberto permite a diversificação da origem das peças, graças à coordenação modular utilizadas pelos diferentes fornecedores (BRUNA, 2017).

São definidas três fases de industrialização da construção: a primeira inicia na Revolução Industrial com a invenção das máquinas; a segunda, no início do século XIX, quando estas começaram a realizar ciclos repetitivos; e a terceira, a partir da segunda metade do século XX, com a utilização de mecanismos para realizarem os trabalhos repetitivos (BRUNA, 2017). Essa periodização não se refere ao contexto brasileiro porque além da industrialização do país ter sido tardia, as inovações tecnológicas da Segunda Revolução Industrial, caracterizada pela terceira fase da industrialização, chegaram no Brasil no final do século XX.

A reconstrução das cidades no pós-guerra foi o contexto de disseminação dos sistemas préfabricados na Europa, já no Brasil, não houve uma situação semelhante. A primeira grande obra 
com pré-moldado de concreto armado foi o hipódromo da Gávea no Rio de Janeiro em 1926 (VASCONCELOS, 2002).

A Era Vargas marcou o início da industrialização no Brasil devido aos investimentos para a criação de empresas estatais. As indústrias foram instaladas principalmente na região Sudeste do país. Nesse contexto, alguns dos arquitetos brasileiros da época adotaram as linhas gerais do Movimento Moderno que estavam sendo discutidas na Europa durante os CIAM. Esses profissionais idealizavam partidos arquitetônicos que integrassem a função, a estética, a técnica construtiva e a economia, sendo assim, incentivadores da pré-fabricação.

No início da década de 1950, o arquiteto Eduardo Kneese de Mello considerava a pré-fabricação como uma possível solução do déficit habitacional brasileiro. Ele projetou residências unifamiliares em São Paulo com componentes pré-fabricados de concreto na sua própria indústria, a Uniseco S.A. que fechou poucos anos depois por diversos motivos, inclusive o fracasso financeiro. Apesar disso, Eduardo Kneese de Mello continuou acreditando nos benefícios da préfabricação e exerceu um importante papel no desenvolvimento da construção industrializada no Brasil (REGINO; PERRONE, 2009).

No final da década de 1950, a Construtora Mauá foi responsável pela construção de diversos galpões industriais em São Paulo com componentes pré-fabricadas de concreto armado produzidas no canteiro de obras (VASCONCELOS, 2002).

Nessa época, a pré-fabricação era utilizada no Brasil com mais frequência na construção de galpões. No entanto, segundo Vasconcelos (2002), o primeiro edifício pré-fabricado de concreto armado com vários pavimentos do país foi o Conjunto Residencial da Universidade de São Paulo (CRUSP) projetado em 1961 pelos arquitetos Eduardo Kneese de Mello, Sidney de Oliveira e Joel Ramalho (fig. 5).

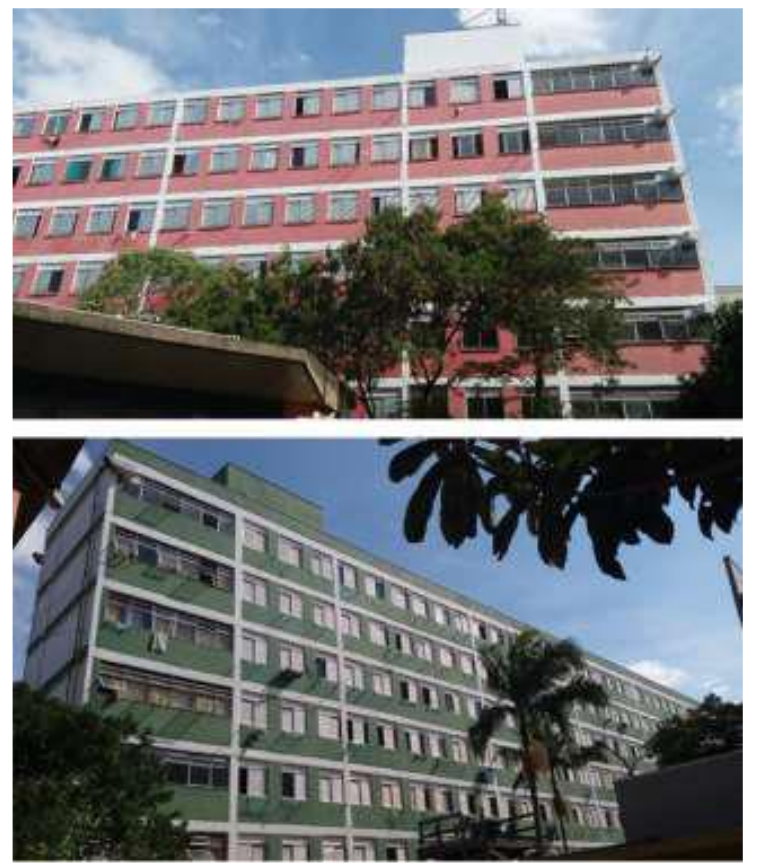

Fig. 5 - Fachadas dos bloco D e E

Fonte: Acervo próprio (2017)

Os arquitetos brasileiros atentados aos princípios no Movimento Moderno defendiam a préfabricação como forma de economia sem subjugar a linguagem arquitetônica. Por outro lado, os galpões pré-fabricados dessa época não foram concebidos com a intenção de integrar a questão estética no projeto, mas também representaram uma inovação na esfera tecnológica da construção civil no país (REGINO; PERRONE, 2009).

Após o Golpe Militar em 1964, foi imposto um regime político sem legitimidade no Brasil, causando revolta em parte da população. Nesse cenário de grande tensão política e econômica, era 
conveniente que fossem tomadas providências públicas para demonstrar a consideração dos apelos populares. Em 1966, foi criado o Banco Nacional de Habitação (BNH) com o intuito de centralizar as operações financeiras do Plano Nacional de Habitação (SANVITTO, 2018).

O rumo da construção civil brasileira estava em discussão devido às questões políticas e ideológicas da época. Alguns profissionais incentivavam o uso da pré-fabricação por conta da economia de materiais e do aumento da produtividade; enquanto outros defendiam que as técnicas construtivas moldadas in loco deveriam continuar sendo empregadas extensivamente para absorver uma mão de obra sem qualificação nos canteiros de obra. Nesse período, o BNH chegou a desestimular a pré-fabricação com o objetivo de promover emprego nos canteiros (PIGOZZO et al., 2006). Mesmo assim, algumas empresas apostaram na utilização de sistemas construtivos industrializados e conseguiram produzir conjuntos habitacionais que foram financiadas pelo órgão federal.

Uma delas foi a Engenharia de Fundações S.A. (Engefusa) que desenvolveu o Sistema Engefusa (fig. 6) baseado em tecnologias importadas. O sistema construtivo era com painéis pré-fabricados de concreto armado e foi utilizado na construção de diversos conjuntos habitacionais no Rio de Janeiro, como o Padre Anchieta em 1966 com 252 apartamentos, o Parque Novo Irajá em 1967 com 192 unidade, e o Antônio Salema, para 472 famílias distribuídas em 30 edifícios (VASCONCELOS, 2002).

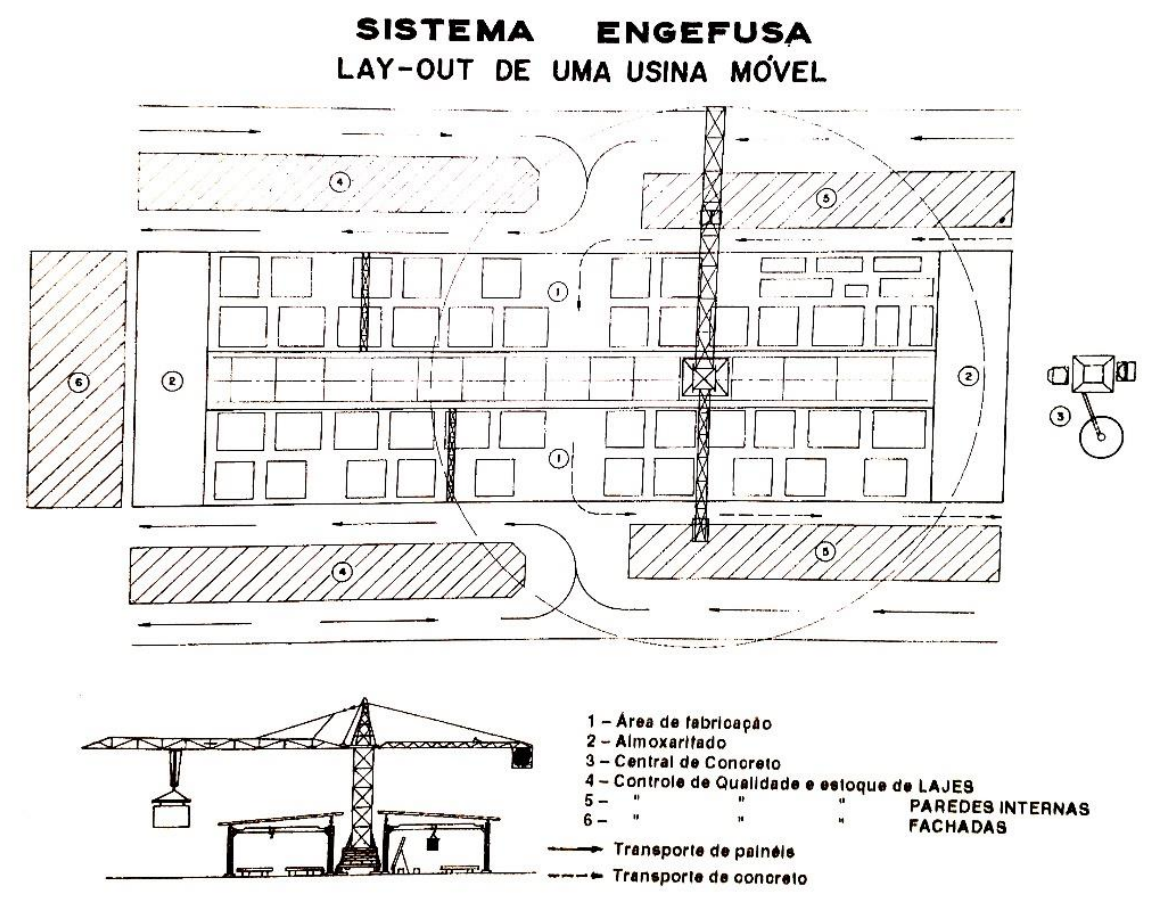

Fig. 6- Sistema Engefusa

Fonte: VASCONCELOS (2002, p. 44)

Segundo Vasconcelos (2002, p. 47), apesar da economia proporcionada pelo sistema construtivo apresentado pelo Eng. Carlos da Silva, a Engefusa faliu depois de alguns anos devido à falta de apoio governamental: “(...) o país perdeu uma grande oportunidade de desenvolver com vigor o sistema implantado pela Engefusa, o que traria grandes benefícios."

O Conjunto Habitacional Zezinho Magalhães Prado, localizado no bairro Cecap em Guarulhos, foi financiado pelo BNH e projetado em 1967 pelos arquitetos Fábio Penteado, João Vilanova Artigas e Paulo Mendes da Rocha. Os edifícios da proposta original eram pré-fabricados de concreto armado com a usina de produção localizada no canteiro de obra. No entanto, o projeto não foi completamente executado e a construção, dividida em diversas fases até ser concluída em 1981, foi realizada com apenas alguns índices de industrialização (CERÁVOLO, 2007). 
Os arquitetos Fábio Penteado, João Vilanova Artigas e Paulo Mendes da Rocha propuseram o Conjunto Zezinho Magalhães do Prado com um sistema construtivo industrializado, fundamentado no discurso da racionalização e economia de recursos. Apesar da sua coerência, o projeto original não foi completamente reproduzido. As licitações optaram pelos orçamentos mais baratos que, naquele momento, não previam a pré-fabricação pelo fato dos sistemas moldados in loco ou com índices de industrialização reduzidos já estarem consolidados no país (CERÁVOLO, 2007).

No caso do CRUSP, projetado 3 anos antes do Conjunto Zezinho Magalhães do Prado, os arquitetos Eduardo Kneese de Mello, Sidney de Oliveira e Joel Ramalho conseguiram um importante adendo na licitação para que a construtora vencedora tivesse o compromisso de executar o sistema construtivo projetado por eles. Os conjuntos habitacionais da Engefusa e da Oxford foram situações sem concorrência com os sistemas convencionais. Assim como Eduardo Kneese de Mello fez na Uniseco, essas construtoras tiveram o interesse de assumir o risco para investir na investigação, desenvolvimento e aplicação de uma nova tecnologia por conta dos benefícios proporcionados por ela e que foram demonstrados no trabalho do Eng. Carlos da Silva. A década de 1970 foi o auge da quantidade de HIS produzidas com recursos do BNH. O programa de financiamento tornou-se mais abrangente e começou a atender outras faixas salariais, afastandose da sua proposta inicial. A qualidade dessa produção é criticada pela dimensão dos conjuntos habitacionais, pela repetição do mesmo modelo de edifício e pela implantação em localizações periféricas. Essa situação originou o termo negativo "padrão BNH", apesar deste ser responsável pelos recursos financeiros utilizados, e não pela autoria dos projetos de arquitetura (SANVITTO, 2018).

Os conjuntos habitacionais construídos com pré-fabricação não correspondem à maior parte da produção do $\mathrm{BNH}$, eles foram frutos do esforço de profissionais que apostaram na tentativa de introduzir novas tecnologias na construção civil brasileira. As críticas discutidas por Sanvitto (2018) correspondem a uma situação semelhante à dos grandes conjuntos europeus do pós-guerra e podem ser constatadas em casos moldados in loco e também com processos industrializados, por tanto, as características negativas dessas HIS não são consequências exclusivas das técnicas construtivas utilizadas.

Nos últimos anos de atuação, o BNH mudou sua postura à respeito de manter a construção convencional e chegou a patrocinar pesquisas sobre novas tecnologias, como a pré-fabricação em concreto armado. No final da década de 1970, foram instalados alguns canteiros experimentais Em 1983, foram constatadas patologias funcionais em alguns edifícios pré-fabricados do BNH. Em alguns casos, o Instituto de Pesquisas Tecnológicas (IPT) concluiu que a demolição seria a melhor alternativa devido ao uso de material inadequado na produção dos componentes estruturais (PIGOZZO et al., 2006).

Em um cenário de recessão econômica, que foi intensificada pela Crise do Petróleo de 1979, o BNH enfrentou outros problemas, como o aumento da inadimplência e a redução de recursos captados, culminando no encerrando de suas atividades em 1986. As funções do órgão suprimido foram atribuídas à Caixa Econômica Federal. Segundo Sanvitto (2018), a implantação, auge e extinção do BNH coincidiram com o início, apogeu e fim do regime militar no Brasil.

Os arquitetos Eduardo Kneese de Mello e Sidney de Oliveira realizaram outros projetos com sistemas construtivos pré-fabricados de concreto, como: o Instituto Nacional da Previdência Social (INPS) Várzea do Carmo em 1967; o Cemitério Vila Paulicéia em 1969; o INPS Vila Maria Zélia em 1976 e a Faculdade de Arquitetura e Urbanismo Farias Brito, atual Universidade de Guarulhos (UnG), em 1980.

O arquiteto João Filgueiras Lima, conhecido como Lelé, também foi um arquiteto introdutor de tecnologias relacionadas com a construção industrializada no cenário brasileiro. No edifício residencial dos professores da Universidade de Brasília em 1962, no Hospital de Taguatinga em 1968 e no Centro de Administração da Bahia foram utilizadas peças de concreto armado préfabricadas (GUERRA; MARQUES, 2015). 
Na década de 1970 o Brasil recebeu diversas empresas multinacionais na região Sudeste. A necessidade de rapidez na conclusão das obras dos edifícios onde essas empresas se instalaram fez com que o sistema construtivo adotado fosse o pré-fabricado de concreto armado. Pelo mesmo motivo, essa solução também foi adotada em edifícios de empresas nacionais.

Em 1984, o arquiteto Oscar Niemeyer projetou os Centros Integrados de Educação Pública (CIEPs). Até 1995, mais de 500 unidades dos CIEPs foram implantadas no estado do Rio de Janeiro (RJ), o que corresponde ao governo de Leonel Brisola, por isso os centros também eram conhecidos popularmente como Brisolões. O objetivo do antropólogo Darcy Ribeiro, responsável pelo programa educacional, era fornecer para cerca de 1000 crianças e adolescentes em cada unidade, atividades acadêmicas e físicas em período integral, incluindo atendimento médico e odontológico (CASTRO, 2009). Os edifícios dos CIEPs são pré-fabricados de concreto armado. As peças foram projetadas por Niemeyer e diversas empresas se comprometeram a produzi-las sem fazer nenhuma alteração (VASCONCELOS, 2002). Atualmente, os edifícios funcionam como escolas da rede pública, mas sem as atividades integradas.

$\mathrm{O}$ arquiteto Lelé foi responsável por experiências com a argamassa armada pré-fabricada. Tanto a argamassa armada, quanto o concreto armado são produzidos com a mesma matéria prima: o cimento Portland e agregados. A diferença entre eles é a granulometria. O tamanho dos agregados é menor no caso da argamassa, possibilitando peças mais delgadas. Esse sistema construtivo foi utilizado foi na década de 1990 nos hospitais da rede SARAH, o de Salvador foi o primeiro a ser construído (CAMPOS et al., 2013).

Na década de 1990 a cidade de São Paulo recebeu grandes investimentos, o que resultou em um aumento significativo na construção de edifícios para uso comercial e de prestação de serviços. Para esses tipos de empreendimentos era conveniente que as obras fossem finalizadas com rapidez sem perder a qualidade da construção. Nesse contexto, a tecnologia de painéis pré-fabricados de fachada foi utilizada em diversos hipermercados, shoppings centers e hotéis (PIGOZZO et al., 2006).

A partir de 2001, os Centros Educacionais Unificados (CEUs) começaram a ser implantados nas áreas periféricas do município de São Paulo. O projeto inicial foi realizado pelos arquitetos Alexandre Delijaicov, André Takyia e Wanderley Ariza; e posteriormente pela equipe do Departamento de Edificações da Prefeitura de São Paulo (EDIF). Os edifícios foram propostos com sistemas construtivos pré-fabricados já existentes no mercado. Essa escolha acelerou o processo de construção, viabilizando a entrega de 21 unidades logo no primeiro ano (ANELLI, 2004).

A Fundação para o Desenvolvimento da Educação (FDE), fundada em 1987, é responsável por construir, manter e adequar escolas no estado de São Paulo. Os escritórios de arquitetura que realizam esses projetos e obras são escolhidos por licitações e devem seguir as diretrizes projetuais fornecidas. No período de 2003 a 2005, a produção de escolas da FDE adotou como partido o emprego de sistemas pré-fabricados de concreto armado (FERREIRA; MELLO, 2006).

O emprego de sistemas construtivos pré-fabricados na produção de escolas públicas foi recorrente devido às vantagens proporcionadas pela economia de recursos e produção em série. Essas escolas fazem parte de programas cuja a intenção é introduzir diversas unidades com a mesma proposta educacional. No caso dos CIEPs e dos CEUs, foram implantados o mesmo modelo de edifício, resultando uma repetição da arquitetura, o que não ocorreu na produção da FDE pois foram realizados diferentes projetos com o mesmo partido arquitetônico.

O Brasil foi sede da Copa do Mundo da Federação Internacional de Futebol (FIFA) em 2014 e dos Jogos Olímpicos do Rio de Janeiro em 2016. Esses grandes eventos esportivos exigem uma estrutura de estádios e arenas que o país não possuía até então. Essas obras iniciaram em 2010 e foram utilizados pré-fabricados de concreto armado para viabilizar o prazo de conclusão. 
Após o fim do BNH, o repasse financeiro para a construção de HIS no Brasil ficou de responsabilidade dos governos estaduais e municipais até 2009, com o surgimento do Programa Minha Casa Minha Vida (PMCMV).

O PMCMV é o maior programa habitacional em vigor no país. A partir de 2012, uma das construtoras de MG iniciou a produção de edifícios de HIS pré-fabricados de concreto armado com o próprio sistema construtivo de pilares, vigas e lajes. Em 2016, outra empresa que desenvolveu seu sistema, construiu um conjunto habitacional em Rio Claro, SP, com painéis de laje e de parede pré-fabricados de concreto armado (fig. 7). No entanto, são experiências isoladas no contexto de produção habitacional brasileiro.

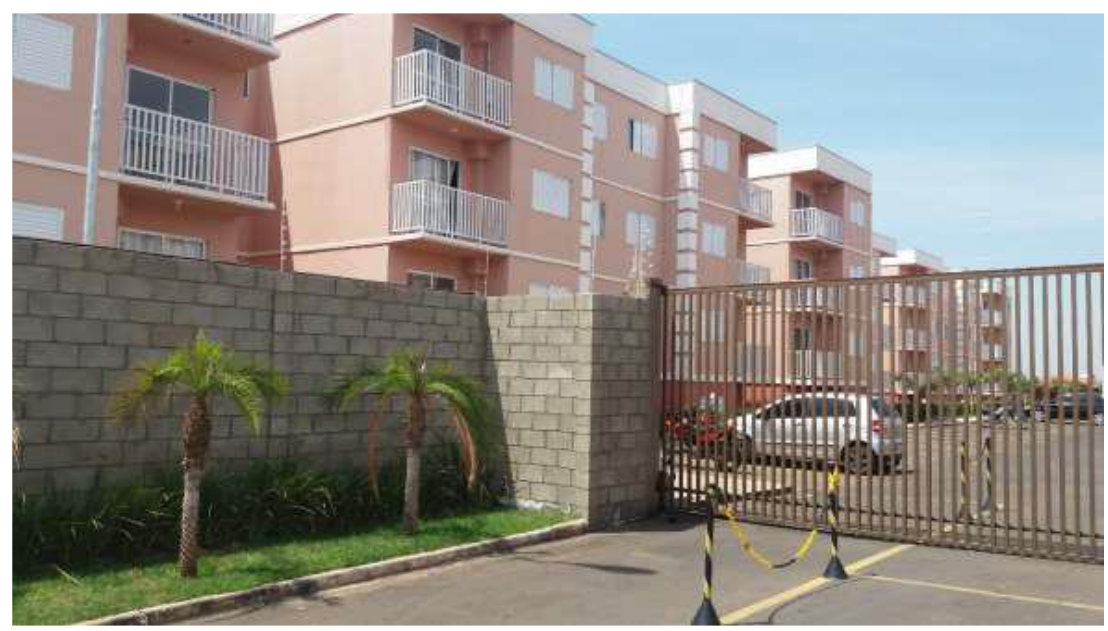

Fig. 7 - PMCMV em Rio Claro, SP

Fonte: Acervo próprio (2017)

A falta de apoio político é um dos empecilhos para a disseminação da pré-fabricação no Brasil, isso ocorre pelo fato de haver interesse econômico em manter as técnicas construtivas convencionais visando à absorção extensiva de mão de obra. Doniak (2017) aponta o sistema tributário do país como um dos principais desafios devido à incidência do Imposto sobre Circulação de Mercadorias e Sobre Prestação de Serviços (ICMS). O mesmo não ocorre com o concreto usinado pois é considerado uma prestação de serviço. Essa situação inviabiliza, em alguns casos, o uso de pré-fabricados, mesmo sendo uma obra mais rápida e com menos desperdício.

Os sistemas construtivos pré-fabricados de concreto armado continuam sendo empregados no Brasil sem destaque na produção habitacional do país. Mesmo dentro do PMCMV, cujo objetivo é construir uma grande quantidade de HIS, os casos construídos com essa tecnologia não são recorrentes apesar de promoverem benefícios adequados para esse uso.

\section{CONSIDERAÇÕES FINAIS}

Apesar das características da pré-fabricação serem consideravelmente vantajosas para a construção civil, essa técnica construtiva nunca fora utilizada em grande escala no Brasil para a produção habitacional. Foram registradas algumas experiências isoladas, como o Conjunto Residencial da Universidade de São Paulo (CRUSP), alguns edifícios do período do Banco Nacional da Habitação (BNH) e, atualmente, do Programa Minha Casa Minha Vida (PMCMV). Essa situação mostra uma incoerência dos programas habitacionais que buscam atender ao déficit habitacional brasileiro com técnicas construtivas moldadas in loco. A falta de apoio político e o estigma atribuído à préfabricação, devido aos conjuntos habitacionais do período pós-guerra na Europa, são os principais empecilhos para a disseminação desta tecnologia no país. 


\section{REFERÊNCIAS}

ANELLI, Renato Luis Sobral. Centros Educacionais Unificados: arquitetura e educação em São Paulo. Revista Arquitextos, $\mathrm{n}^{\circ}$ 055.02. São Paulo: Portal Vitruvius, 2004. Disponível em: http://www.vitruvius.com.br/revistas/read/arquitextos/05.055/517 Acesso em: 24 mar. 2018.

BRUNA, Paulo. Arquitetura, industrialização e desenvolvimento. $2^{\circ}$ ed. São Paulo: Editora Perspectiva, 2017 ( $1^{\circ}$ ed. 1941).

CAMPOS, Paulo Eduardo Fonseca de et al. Microconreto de Alto Desempeño: La tecnologia del MicroCAD aplicada em la construcción del hábitat social. São Paulo: Mandraim, 2013.

CERÁVOlo, Fabiana. A Pré-fabricação em Concreto Armado Aplicada a Conjuntos Habitacionais no Brasil - O caso do Conjunto Zezinho Magalhães Prado. Dissertação (Mestrado em Arquitetura e Urbanismo) - Faculdade de Arquitetura e Urbanismo de São Carlos: São Carlos, 2007.

CONRADS, Ulrich. Programs and Manifestoes on 20th-Century Architecture. Cambridge: MIT Press, 1970, p. 109-115 (tradução nossa).

DONIAK, Íria Lícia Oliva. Entrevista com a Presidente Executiva da Associação Brasileira da Construção Industrializada de Concreto (ABCIC). São Paulo, 06 out. de 2017

DUFAUX, Frédéric; FORCAUT, Annie. Le monde des grands ensembles: Sur l'origine des grands ensembles. Paris: Créaphis, 2004.

FERREIRA, Avany de Francisco; MELLO, Mirela Geiger de. Arquitetura Escolar Paulista: Estruturas Pré-Fabricadas. São Paulo: FDE, 2006.

FRANKFURT, Institut für Stadtgeschichte Frankfurt. Praunheim under construction, 1926, n.p. In: GAILHOFER, Sunna. 90 Years of Frankfurt's Praunheim Estate. Goethe Institut, Culture, Urban Planing. Frankfurt, 2016. Disponível em: https://www.goethe.de/en/kul/arc/20814957.html Acesso em: 17 nov. 2017.

GAILHOFER, Sunna. 90 Years of Frankfurt's Praunheim Estate. Goethe Institut, Culture, Urban Planing. Frankfurt, 2016. Disponível em: https://www.goethe.de/en/kul/arc/20814957.html Acesso em: 17 nov. 2017.

GUERRA, Abílio; MARQUES, André. João Filgueira Lima: Ecologia e Racionalização. Revista Arquitextos, ano 16, n 181-03, São Paulo: Vitruvius, 2015. Disponível em http://www.vitruvius.com.br/revistas/read/arquitextos/16.181/5592 Acesso em 07 dez. 2017.

GROPIUS, Walter. Bauhausucher .Albert Laneen: Munique, 1924. Apud GUINSBURG, Jacob; KOUDELA, Ingrid. Bauhaus: Novarquitetura. $6^{\circ} \mathrm{ed}$. São Paulo: Editora Perspectiva, 2013.

HOBSBAWM, Eric John Ernest. Era dos Extremos: O Breve Século XX (1914-1991). São Paulo: Companhia das Letras, 2009. 
L'ARCHITECTURE D'AUJOURD'HUI. Chantier experimental Pont des Sèvres. n 45, 1952, p. 4 In: CERCEAU, Julien. Préfabriquer le logement d'après-guerre. Bernard Zehrfuss, acteur représentatif d'une époque. Master Habitat \& Énergie. École d'architecture de la ville et des territoires à Marne-la-Vallée, 2013. Disponível em: http://mes.marnelavallee.archi.fr/mes/072012379.pdf . Acesso em: 31 out. 2017.

MILMAN, Boruch. A pré-fabricação de edifícios. Universidade Federal do Rio de Janeiro (UFRJ) Rio de Janeiro, 1971.

PIGOZZO, Bruno et al. A influência dos pré-fabricados em concreto armado no ciclo de industrialização da construção. XI Encontro Nacional de Tecnologia no Ambiente Construído, Florianópolis, 2006. Disponível em:

http://www.infohab.org.br/entac2014/2006/artigos/ENTAC2006_3265_3274.pdf Acesso em: 21 set. 2016.

POLETO, Sálua Kairuz Manoel. Referências europeias de arquitetura e urbanismo nas origens da produção de habitação de interesse social no Brasil (1930-1964). Tese (Doutorado em Teoria e História Arquitetura e Urbanismo) na Escola de Engenharia de São Carlos da Universidade de São Paulo (USP): São Carlos: USP, 2011.

REGINO, Aline Nassaralla; PERRONE, Rafael Antonio Cunha. Eduardo Augusto Kneese de Mello: sua contribuição para habitação coletiva em São Paulo. Revista Risco de Pesquisa em Arquitetura e Urbanismo. Programa de Pós-graduação do departamento de Arquitetura e Urbanismo da Universidade de São Paulo. São Paulo: EESC-USP, 2009, p. 57-97. Disponível em: http://www.iau.usp.br/revista_risco/Risco9-pdf/02_art04_risco9.pdf Acesso em: 04 dez. 2017.

SANVITTO, Maria Luiza Adams. As Habitações de Interesse Social com Recursos do Banco Nacional da Habitação No Brasil 1964-1986. In: III Congreso Internacional de Vivienda Sostenible, 2018, Guadalajara. Actas del III Congreso Internacional de Vivienda Sostenible, 2018.

SERAFINI, Tonino; VINCENDON, Sibylle. Grands ensembles: démolir les clichés, pas les cités. Libération. Acesso online: Paris, 2015. Disponível em: http://www.liberation.fr/france/2015/10/07/non-ce-n-est-pas-de-la-camelote-demolir-les-clichespas-les-cites-non-ce-n-est-pas-une-aberration-ur_1399302. Acesso em: 08 out. 2017.

VASCONCELOS, Augusto Carlos. O concreto no Brasil: Pré-fabricação, Monumentos, Fundações. Vol. III. São Paulo: Editora Studio Nobel, 2002.

VILLAÇA, Flávio. O que todo cidadão deve saber sobre habitação. São Paulo: Global Editora, 1986. 